sions that I ask you to find room in your pages for this short protest.

Middle Class Schools, I.ittlehampton, January I3

\section{A Solar Halo}

A PHENOMENON quite unusual in these parts was witnessed here this morning in the form of a solar halo of surpassing brilliancy. The outer ring was dazzling white; the next pale lemon, the inner orange, and the inclosed space grayish brown, uniform throughout. The display was brightest at sunrise. The sky was clear with the exception of a few light clouds along the eastern horizon. The air was still. The temperature was ten degrees below freezing point. As the sun climbed higher the colours gradually faded out, until at 10.30 the last traces had disappeared.

Mansfield, Pa., U.S.A., January Io

\section{Coltsfoot}

THERE is an interesting article on "Coltsfoot" in the Pall Mall for January 21, in which mention is made of fifty-two species of wild flowers being in bloom at Lyme Regis; "and at Hastings nearly one hundred have been counted within a semicircular radius of ro miles." Coltsfoot is amongst the flowers already in blossom on the south coast ; and it is instanced as a very remarkable proof of the mildness of this winter. I think it is nearly as wonderful that Corylus avellana, the common nut, should be in blossom on a sheltered bank in North Wiltshire. Not only are the catkins fully in blow, but the fertile flowers are also in blos:om, and that not only on one, but on many bushes. A wood full of primroses such as we often wait for till March or April is another instance of absence of frost.

Salthrop, Wroughton, Wilts., January 23 T. S. MASKELYNE

\section{The Absolute Sine Electrometer}

IN my paper in last week's NATURE (p. 278), read " $\frac{1}{60}$ inch pitch" instead of " $\frac{1}{16}$ inch pitch" for the micrometer screw. The diagram has been turned round counterclockwise.

Cooper's Hill, January 21 George M. Minchin

PEDiculi. - A correspondent asks if any one can inform him whether in experimental researches on spontaneous generation pediculi have ever been the subjects of observation, and if so, with what results? Further, is it likely that the density of their dermal structures affords them a means of resistance to heat applied through a liquid medium?

\section{PHYSICAL NOTES}

DR. R. KöNIG has recently described a method of investigating the nodes in the vibrating column of air in an organ-pipe. The pipe-a large one-is laid horizontally on its back, and a long slit is made the whole length of the pipe. The slit is closed by water, the pipe lying in a trough. A small curved tube, open at the end, passes down through the water and up through the slit into the pipe. Its other end is joined to a manometric capsule in conjunction with a flame apparatus of the usual type. The nodal surfaces can be determined to within two millimetres. The introduction of the tube interferes less with the conditions of vibration than the introduction of a tissue-paper disk or other explorer hitherto $u$ ed.

A NEW barometer, automatically recording the variations on an enlarged scale, has been iavented by Marshall Delaey (Bull. Belg. Acad., No. 8). It has the following arrangement:-The barometric tube, having a capacious reservoir at top, is fixedly suspended. The cistern is a tube slightly wider and nearly as long; it bears on oxe side an index, and on the other a pencil working on a moving cylindrical surface, and it forms the upper part of a kind of areometer, having a downward extension in the form of a closed tube floating in mercury in a wider tube, which communicates below, through a U-tube, with a wide and shallow covered cistern, the level in which is approximately constant. The variation of pressure is marked by the variation of the height of mercury in the reservoir, and this latter is to that of the total height in the barometric cistern (or to the path of the float or of the pencil) in the ratio of the section of the cistern to that of the reservoir (a sixth in the instrument the author represents). Thus an a.mplification is realised.
THE colourless fluorspar of Switzerland, according to $\mathbf{M}$. Cornu (Four. de Phys., October), is a substance at least as tr insparent for ultra-violet rays as quartz, and its law of dispersion is so much in harmony with that of quartz that with the two a system of lenses of nearly perfect achromatism may be had. To give an idea of this achromatism M. Cornu states that he obtains on one clické, with very satisfactory distinctness, the spectrum of all the photographic lines of metals, from the three blue lines of zinc to the lines No. 32 of aluminium. With such objectives a determination of the wave-lengths of very refrangible radiations becomes possible. The author describes measurements of $t$ is kind (along with details of method) in the case of magnesium, cadmium, zinc, and aluminium.

A RHEOMETER, for measuring currents at different depths in water, is described by Signor Scardona in the Rivista Scientifico. Industriale (September 30). It acts by pulses generated at intervals (according to the speed of the current) in a tube, and affecting a bell. The water-current acts on two screw-vanes on a horizontal shaft in a case attached to a vertical rod. This shaft (which a flat vane keeps in a line with the current) actuates, at intervals, through an endless screw and a reducing system of wheels, a lever applied to a caoutchouc capsule at the end of a metallic tube, through which, and a flexible tube attached, the resulting pulses pass to the bell-arrangement (which is in a portable case). The rod and the metallic tube are each made up of several pieces screwed together, and the vane case and tube can be fixed at any part of the rod. The advantages claimed over Amsler's rheometer are simplicity (in dispensing with electrical action), and a better kind of signal (one stroke of the bell for each turn of a wheel).

AN experimental inquiry by Herr Graetz (Wied. Ann. No. Io) into the heat-conductivity of gases and its relation to temperature results as follows:-I. Heat-conduction in the gases air, hydrogen, and (with low temperatures) carbonic acid, consists in transference of progressive energy only; intramolecular energy contributes immeasurably little. The molecules thus behave like material points. 2. The relation of heat conduction to temperature is found by experiment to be such (approximately) as Clausius' theory requires. 3. All results for gases and vapours, showing divergences from the values calculated from theory, are without evidential force, for they only gave the apparent heatconducting power, in consequence of absorntion of radiant heat. 4. The divergence of the temperature-coefficient of friction from that calculated from theory cannot have for cause (or not alone) the decrease of the molecular diameter with rising temperature; some other explanation must be sought.

A USEFUL Comparison of the numerous determinations of the expansion of water by heat is made by Herr Volkmann in a paper contributed to Königsberg Institute (Wied. Ann. No. IO). Experimenters, it is known, have used two methods-the hydrostatic and the dilatometric. The author gives in a table the average values for volume and density of water (deduced from the observations of Hagen, Matthiessen, Pierre, Kopp, and Jolly) for all temperatures from zero to $25^{\circ}$; also the volumes every $5^{\circ}$ from $25^{\circ}$ up to $100^{\circ}$. The temperature of greatest density of vater is, according to the best data, $+3^{\circ} 94^{\circ} \mathrm{C}$. Herr Volkmamn thinks there is no occasion to study the subject anew on the lines hitherto adopted; but it might be well (in his opinion) to observe the absolute expansion of water in the same way as Regnault determined that of mercury (with communicating tubes).

IN view of assertions that the band-spectrum attributed to hydrogen by Herr. Wiillner is really that of a hydrocarbonacetylene according to Herr Ciamician-the former physicist has made a careful examination of the acetylene spectrum (Wied. Ann. No. 10), and finds that, as might be expected from the higher proportion of carbon in acetylene, its spectrum differs from that of hydrogen much more than do the spectra of ethylene and marsh gas. While in these latter the characteristic carbon bands indicate the spectrum to be that of a carbon-containing gas, the whole of the red, orange, and yellow part, in the other, resembles much more the spectrum of carbonic acid than it does that of hydrogen.

THE physical properties of indium have been very little known hitherto. A recent contribution on the subject by Herr Erhard (Wied. Ann. No. I I) treats of some of its electric properties. As regards resistance, he finds that indium is like some other metals in not coming under the often-accepted-rule that pure metals have a change of coefficient of resistance with tempera- 